University of Nebraska - Lincoln

DigitalCommons@University of Nebraska - Lincoln

USDA Forest Service / UNL Faculty Publications U.S. Department of Agriculture: Forest Service -National Agroforestry Center

2006

Regression modeling and mapping of coniferous forest basal area and tree density from discrete-return lidar and multispectral satellite data

\author{
Andrew T. Hudak \\ Rocky Mountain Research Station, ahudak@fs.fed.us \\ Nicholas L. Crookston \\ Rocky Mountain Research Station, ncrookston@fs.fed.us \\ Jeffrey S. Evans \\ Rocky Mountain Research Station \\ Michael J. Falkowski \\ University of Idaho, Falk4587@uidaho.edu \\ Alistair M.S. Smith \\ University of Idaho, alistair@uidaho.edu \\ See next page for additional authors
}

Follow this and additional works at: https://digitalcommons.unl.edu/usdafsfacpub

Hudak, Andrew T.; Crookston, Nicholas L.; Evans, Jeffrey S.; Falkowski, Michael J.; Smith, Alistair M.S.; Gessler, Paul E.; and Morgan, Penelope, "Regression modeling and mapping of coniferous forest basal area and tree density from discrete-return lidar and multispectral satellite data" (2006). USDA Forest Service / UNL Faculty Publications. 184.

https://digitalcommons.unl.edu/usdafsfacpub/184

This Article is brought to you for free and open access by the U.S. Department of Agriculture: Forest Service -National Agroforestry Center at DigitalCommons@University of Nebraska - Lincoln. It has been accepted for inclusion in USDA Forest Service / UNL Faculty Publications by an authorized administrator of DigitalCommons@University of Nebraska - Lincoln. 


\section{Authors}

Andrew T. Hudak, Nicholas L. Crookston, Jeffrey S. Evans, Michael J. Falkowski, Alistair M.S. Smith, Paul E. Gessler, and Penelope Morgan 


\title{
Regression modeling and mapping of coniferous forest basal area and tree density from discrete-return lidar and multispectral satellite data
}

\author{
Andrew T. Hudak, Nicholas L. Crookston, Jeffrey S. Evans, Michael J. Falkowski, \\ Alistair M.S. Smith, Paul E. Gessler, and Penelope Morgan
}

\begin{abstract}
We compared the utility of discrete-return light detection and ranging (lidar) data and multispectral satellite imagery, and their integration, for modeling and mapping basal area and tree density across two diverse coniferous forest landscapes in north-central Idaho. We applied multiple linear regression models subset from a suite of 26 predictor variables derived from discrete-return lidar data ( $2 \mathrm{~m}$ post spacing), advanced land imager (ALI) multispectral (30 $\mathrm{m})$ and panchromatic $(10 \mathrm{~m})$ data, or geographic $X, Y$, and $Z$ location. In general, the lidar-derived variables had greater utility than the ALI variables for predicting the response variables, especially basal area. The variables most useful for predicting basal area were lidar height variables, followed by lidar intensity; those most useful for predicting tree density were lidar canopy cover variables, again followed by lidar intensity. The best integrated models selected via a best-subsets procedure explained $\sim 90 \%$ of variance in both response variables. Natural-logarithm-transformed response variables were modeled. Predictions were then transformed from the natural logarithm scale back to the natural scale, corrected for transformation bias, and mapped across the two study areas. This study demonstrates that fundamental forest structure attributes can be modeled to acceptable accuracy and mapped with currently available remote sensing technologies.
\end{abstract}

Résumé. Nous avons comparé l'utilité du lidar à retour discret et de l'imagerie satellitaire multispectrale et leur intégration pour la modélisation et la cartographie de la surface terrière et la densité des arbres pour deux paysages diversifiés de forêts de conifères dans le centre-nord de l'Idaho. Nous avons appliqué les sous-ensembles des modèles de régression linéaire multiple d'une série de 26 variables prédictives dérivées de données lidar à retour discret (post-espacement de $2 \mathrm{~m}$ ), de données multispectrales $(30 \mathrm{~m}$ ) et panchromatiques $(10 \mathrm{~m})$ du capteur ALI (《advanced land imager ») ou de localisation géographique en $X, Y$ et $Z$. En général, les variables dérivées du lidar étaient d'une plus grande utilité que les variables ALI pour la prévision des variables dépendantes, particulièrement la surface terrière. Les variables les plus utiles pour la prévision de la surface terrière des arbres étaient les variables lidar de la hauteur des arbres suivies par l'intensité lidar ; les plus utiles pour la prévision de la densité des arbres étaient les variables lidar du couvert, là aussi suivies par l'intensité lidar. Les meilleurs modèles intégrés sélectionnés via une procédure du meilleur sous-ensemble a permis d'expliquer $~ 90 \%$ de la variance pour les deux vaiables dépendantes. Les variables dépendantes transformées par logarithme naturel ont été modélisées. Les prévisions ont alors été transformées de l'échelle ln, puis à l'échelle naturelle, corrigées pour le biais lié à la transformation et cartographiées sur l'ensemble des deux régions d'étude. Cette étude démontre que les attributs fondamentaux de la structure forestière peuvent être modélisés avec une précision acceptable et cartographiés au moyen de technologies de télédétection disponibles à l'heure actuelle.

[Traduit par la Rédaction]

\section{Introduction}

Measures of stand structure are needed to manage forested landscapes for multiple purposes, including timber production, wildlife habitat, and fire hazard. Remote sensing of forest structure has proven challenging for forest operational managers and planners, many of whom still rely on aerial photograph surveys to meet user accuracy requirements. Although moderate-resolution satellite imagery (e.g., Landsat) is reasonably sensitive to variation between managed forest stands, it is insensitive to canopy height variation within stands compared to aerial photography. Laser altimetry and light detection and ranging (lidar) systems, on the other hand, actively measure height to the reflective surface. Most commercially available discrete-return lidar systems can accurately measure top-of-canopy height and ground height, as well as canopy layers in between. Recognizing that passive imaging and active lidar systems sense fundamentally different

Received 30 September 2005. Accepted 26 January 2006.

A.T. Hudak, ${ }^{1}$ N.L. Crookston, and J.S. Evans. Rocky Mountain Research Station, US Department of Agriculture Forest Service, 1221 South Main Street, Moscow, ID 83843, USA.

M.J. Falkowski, A.M.S. Smith, P.E. Gessler, and P. Morgan. Department of Forest Resources, University of Idaho, Sixth \& Line Streets, Moscow, ID 83844-1133, USA.

${ }^{1}$ Corresponding author (e-mail: ahudak@fs.fed.us). 
aspects of forest structure, and that probably no single remote sensor can provide all of the information useful and relevant to forest managers, the integration of image and lidar data for the purpose of predicting, mapping, managing, and monitoring forest structure attributes is a logical and worthwhile pursuit (Lefsky et al., 1999; Hudak et al., 2002).

Landsat imagery has become the standard relied upon by many forest ecologists and managers who use remotely sensed data (Cohen and Goward, 2004). Landsat data coverage began with the launch of Landsat-1 in 1972. Landsat-5 operated far beyond its expected lifespan, from 1984 until 26 November 2005 , when the appearance of a solar array drive anomaly briefly halted imaging (http://landsat.usgs.gov/technical_details/ investigations/15_solar_drive.php). Landsat-7 was launched and has operated since 1999, although with reduced utility since a scan line corrector anomaly began on 31 May 2003 (http://landsat. usgs.gov/programnews.html). Considering the declining availability of new Landsat imagery, there is justifiable concern for maintaining Landsat data continuity, particularly until the launch of the Landsat data continuity mission (LDCM) operational land imager (OLI), which will provide Landsat-like imagery but is expected no sooner than late 2009 (http://ldcm. usgs.gov/).

The advanced land imager (ALI) satellite sensor was designed in part to provide data continuity with the Landsat-5 thematic mapper (TM) and Landsat-7 enhanced thematic mapper plus (ETM+) sensors (http://eo1.usgs.gov/ali.php). Although the ALI swath width $(37 \mathrm{~km})$ is more restricted than that of Landsat $(185 \mathrm{~km})$, and ALI acquisitions must be scheduled in advance, the ALI sensor is pointable. The ALI measures solar irradiance in nine multispectral bands between 0.433 and $2.350 \mu \mathrm{m}$ in the electromagnetic spectrum, matching the six multispectral bands of Landsat TM or ETM+, plus an additional three bands. The spatial resolution of the panchromatic (PAN) band is $10 \mathrm{~m}$, an improvement over the $15 \mathrm{~m}$ resolution of the ETM+ panchromatic band. Furthermore, ALI data are 16-bit rather than 8-bit, offering greater dynamic range. In a comparative study, Bryant et al. (2003) found no disadvantages of the ALI sensor relative to the TM or ETM+ sensors and recommended the ALI sensor for a potential Landsat-8 payload.

Efforts to model and map height and related attributes from satellite imagery alone have generally been too inaccurate for forest operational managers. Canopy height is particularly valued by foresters because it relates strongly to other structure attributes of interest, such as basal area and biomass. Numerous studies have demonstrated the utility of lidar for characterizing various attributes of forest canopy structure from discretereturn lidar data (Nelson, 1984; Nilsson, 1996; Means et al., 2000). Enthusiasm for lidar-based forest inventory is driving expansion of the commercial lidar industry (Flood, 2001). As the costs of managing forested landscapes increase in a competitive environment, commercial timber and paper companies are increasingly turning to lidar for potentially more accurate and efficient inventory and assessment of their forest resources.
Our objective was to compare the relative utility of discretereturn lidar data and ALI satellite imagery, and their integration, for modeling and mapping basal area and tree density across two spatially disjunct coniferous forest landscapes situated along a single biomass and productivity gradient in northern Idaho. Many researchers have recognized the potential of remote sensing data integration, making "data integration" a broad term that needs to be more narrowly defined. Lefsky et al. (2001) compared the utility of several remote sensing data types for accurately characterizing high-biomass forest structure in western Oregon and found that lidar outperformed digital aerial photography, hyperspectral aerial imagery, and multispectral satellite imagery. Rather than evaluate many remote sensing products, we used single acquisitions of discrete-return lidar data and multispectral satellite imagery, much like a commercial forester with limited time and resources might do. Popescu and Wynne (2004) fused lidar and multispectral image data to improve estimates of individual tree height in eastern forests. Rather than examine individual tree attributes, we focused on stand attributes of interest to planners and managers of large forested landscapes. Lastly, rather than "fuse" remotely sensed data layers, or test a variety of data integration methods, we focused on the simple and widely applicable method of multiple linear regression. Hence the data integration conducted in this analysis is purely statistical but provides an accessible means of selecting remotely sensed predictor variables and evaluating alternative models. This study is intended to demonstrate to forest planners and operational managers that it is within their means to model and map fundamental stand structure variables of interest to acceptable accuracy with current lidar and imaging technologies.

\section{Methods}

\section{Study area}

The Moscow Mountain and St. Joe Woodlands study areas together make up more than 88000 ha in north-central Idaho (Figure 1). Moscow Mountain is nearly wholly surrounded by agricultural land, and the St. Joe Woodlands lies within the regional block of mixed conifer forest type. Both areas are topographically diverse, with the higher elevations and steeper slopes occurring in the St. Joe Woodlands. Wind-blown volcanic ash from the Cascade Mountains acts as an important soil component in both areas. Conifer species range along a moisture gradient from Pinus ponderosa and Pseudotsuga menziesii at the drier end (more commonly found on southern aspects in the Moscow Mountain area) to Thuja plicata and Tsuga heterophylla at the wetter end (more commonly found on northern aspects, especially in the St. Joe Woodlands). Other important species include Abies grandis, Abies lasiocarpa, Larix occidentalis, Picea engelmannii, Pinus albicaulis, Pinus contorta, and Pinus monticola. These forests are actively managed. Most have been logged at least once; very little land has never been logged. Two industry partners in this study, Bennett Lumber Products, Inc. and Potlatch, Inc., are the 
principal landowners of Moscow Mountain and the St. Joe Woodlands, respectively. The University of Idaho Experimental Forest and St. Joe Ranger District of the Idaho Panhandle National Forest occupy sizable portions of Moscow Mountain and the St. Joe Woodlands, respectively. There are more private landowners and structures on Moscow Mountain, given its proximity to Moscow and other farming and logging communities.

\section{Field sampling}

Field sites were selected in each study area using a two-stage stratified design, with the first stage based on three elevation and three solar insolation classes generated from a $30 \mathrm{~m}$ US Geological Survey digital elevation model (DEM) and crossed to produce nine strata. Solar insolation, which incorporates into a single variable the important biophysical drivers of slope and aspect, was generated using Solar Analyst (Helios Environmental Modeling Institute (HEMI), LLC, 2000). The second stage assigned nine leaf area index (LAI) classes into each of the nine strata, where LAI was indicated by a midinfrared corrected normalized difference vegetation index (NDVIc) (Nemani et al., 1993; Pocewicz et al., 2004) calculated from an 18 August 2002 Landsat ETM+ multispectral image. The three classifications were then combined systematically, and pixels within the resulting strata were selected randomly, resulting in 81 target plots irregularly distributed across each study area. These target plots were loaded as waypoints into a Trimble ProXR global positioning system (GPS) to navigate to in the field.

Once found in the field, plot centers were geolocated using the GPS by logging a minimum of 150 points; these were later differentially corrected upon returning from the field and then averaged to get a final three-dimensional (3D) point position accurate to within $\pm 0.8 \mathrm{~m}$ horizontally and $\pm 1.1 \mathrm{~m}$ vertically, according to the commercial GPS software (Trimble Pathfinder Office). If the plot happened to span a road, the plot center was moved just far enough to place the entire plot within the stand structural condition being characterized. If a plot was otherwise unsafe to sample (e.g., too steep), it was discarded and an alternative pixel from the same stratum was selected as a target plot. The sizes of the fixed-radius plots were 0.04 ha ( 0.1 acre) at Moscow Mountain and 0.08 ha $(0.2$ acre $)$ at the St. Joe Woodlands. Within each plot, all trees with $\geq 12.7 \mathrm{~cm}$ (5 in.) diameter at breast height ( $\mathrm{dbh}$ ) were measured (ignoring trees with $\mathrm{dbh}<12.7 \mathrm{~cm}$ ). Eleven plots at Moscow Mountain lacked trees $\geq 12.7 \mathrm{~cm}$ dbh but were included in this analysis. In addition, two supplementary plots were sampled to characterize old-growth structure (one plot in each study area). Old-growth structure is rare and hence was not selected through the stratification process. However, we considered sampling the

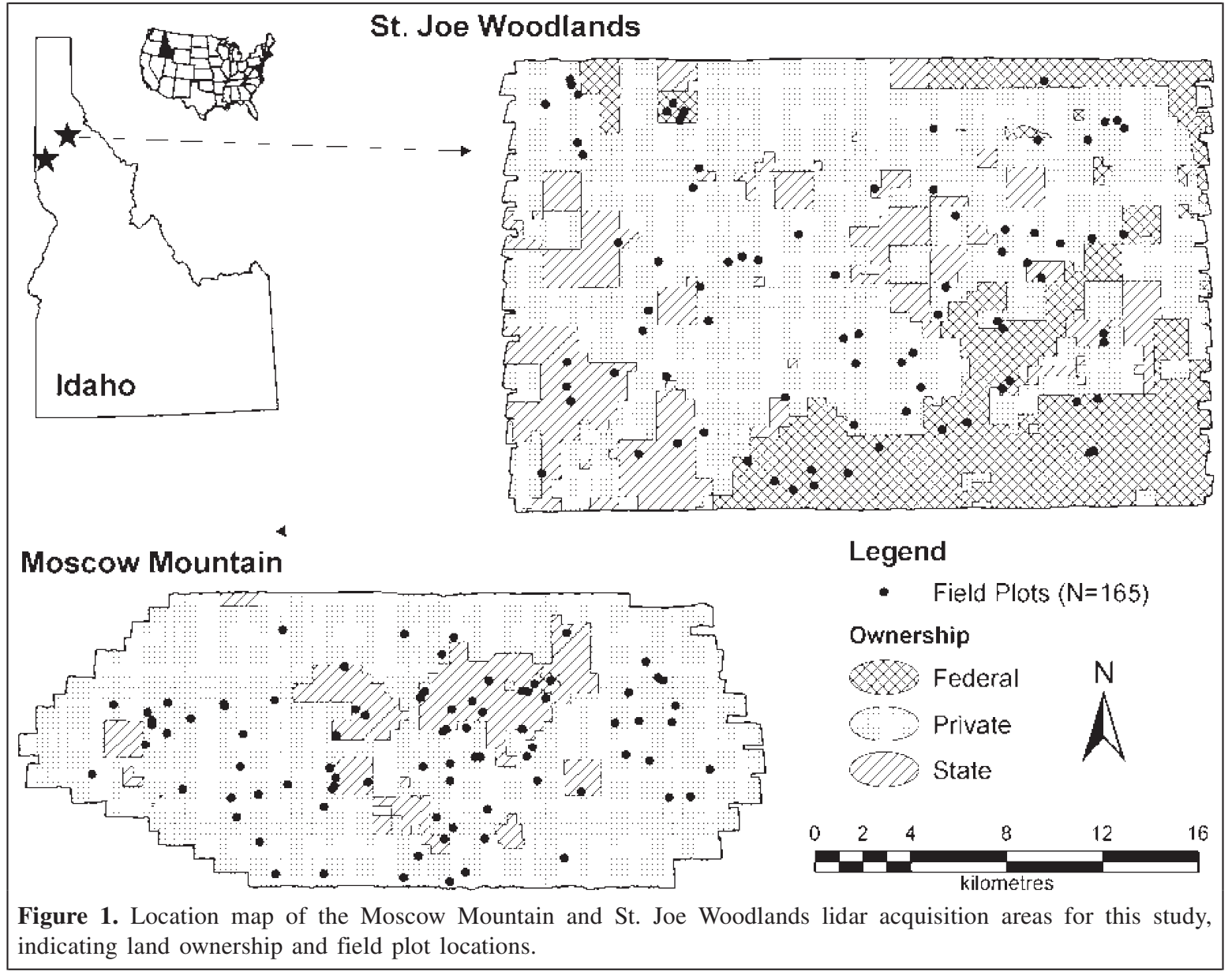


upper end of the vegetation biomass gradient important and interesting to both managers and researchers. Although the two old-growth stands were necessarily subjectively selected, the plot centers within each stand were randomly located. The final plot tallies were 84 for Moscow Mountain and 81 for the St. Joe Woodlands.

\section{Image processing}

ALI satellite images were acquired on 1 October 2004 for Moscow Mountain $\left(46.8617^{\circ} \mathrm{N}, 116.9642^{\circ} \mathrm{W}\right)$ from an overhead path (look angle $=3.3692^{\circ}$ ) and on 3 October 2004 for the St. Joe Woodlands $\left(47.2713^{\circ} \mathrm{N}, 116.3233^{\circ} \mathrm{W}\right)$ from an east path (look angle $=-12.1905^{\circ}$ ). The Level $1 \mathrm{R}$ products were purchased, which were radiometrically but not geometrically corrected (http://eo1.usgs.gov/userGuide/ali_ process.html). Both the single-band panchromatic and nine-band multispectral images were delivered as four separate image strips, which were mosaicked in Environment for Visualizing Images (ENVI) following detailed online instructions (http://eo1.usgs.gov/faq.php?id=31). The seamless mosaicked images were then coregistered in ERDAS Imagine to an orthorectified Landsat ETM+ panchromatic image base (26 August 1999; path 42, row 27) using image tie-points generated with an automated, area-based correlation algorithm coded in Interactive Data Language (IDL) (Kennedy and Cohen, 2003). For Moscow Mountain, the cumulative root mean square error (RMSE) was $1.9 \mathrm{~m}$ (panchromatic, $N=202$ points) and $8.5 \mathrm{~m}$ (multispectral, $N=78$ points); for the St. Joe Woodlands, the cumulative RMSE was $5.0 \mathrm{~m}$ (panchromatic, $N=82$ points) and $3.6 \mathrm{~m}$ (multispectral, $N=106$ points).

The georectified images were converted into ArcInfo GRIDs. The mean value of pixels intersecting the plot footprint was calculated from each band using the ZONALSTATS function, and in the case of the $10 \mathrm{~m}$ panchromatic band, the standard deviation was also calculated as an index of canopy texture (Hudak and Wessman, 1998).

\section{Lidar processing}

Lidar data were acquired in July, August, or September 2003 (depending on the flight line) for Moscow Mountain (32 708 ha) and the St. Joe Woodlands (55 684 ha) (Figure 1). The lidar system (ALS40) of the vendor (Horizons, Inc., Rapid City, S.Dak.) operated at a wavelength of $1064 \mathrm{~nm}$, which is in the near-infrared region of the electromagnetic spectrum where vegetation and ground are highly reflective, affording a high signal-to-noise ratio in the reflected returns. Raw $X, Y$, and $Z$ positions were delivered as ASCII files corresponding to each flight line. To identify ground returns, a curvature thresholding approach (Haugerud and Harding, 2001) termed "virtual deforestation" (VDF) was used. VDF iteratively identifies and removes nonground (principally vegetation) returns until only ground returns remain. This VDF technique was coded in ArcInfo macro-language (AML) and improved upon by incorporating a progressive interpolation scale and a curvature weighting coefficient into the model, which we have named the progressive curvature filter (http://forest.moscowfsl.wsu.edu/ gems/lidar). Subsequent interpolation of these ground returns using bicubic splines produced a desirable bare earth DEM at a resolution matching the post spacing of the lidar survey $(2 \mathrm{~m})$.

Raw intensity values were interpolated into a $2 \mathrm{~m}$ grid using the POINTINTERP function in GRID with an inverse-distance weighted smoothing function. To indicate nonground returns, the DEM was subtracted from the raw lidar returns, using a minimum height threshold of $17 \mathrm{~cm}$ (the estimated vertical uncertainty of the lidar returns specified by the lidar vendor in the contract). The resulting nonground returns were then binned at a horizontal resolution of $6 \mathrm{~m}$ with the POINTSTATS function to generate raster grids of maximum canopy height. Canopy cover was calculated as the percentage of nonground returns out of the total returns within each $6 \mathrm{~m}$ cell. In these study areas, the nonground returns reflect almost exclusively overstory or understory vegetation, although there are a few buildings, radio towers, power lines, etc.

The ZONALSTATS function was used to calculate mean, standard deviation, minimum, and maximum statistics of grid cells intersecting the plot footprint, from the intensity, height, and canopy cover layers. In anticipation of mapping some of these variables, the FOCALMEAN, FOCALSTD, FOCALMIN, and FOCALMAX filter functions were also passed over the intensity, height, and cover layers to produce output grids of these statistics. The DEM was used as the image layer for mapping elevation. From the DEM, $10 \mathrm{~m}$ Universal Transverse Mercator (UTM) easting and northing grids were generated in GRID using a simple DOCELL function (also in anticipation of using the easting and northing grids later as inputs for mapping the response variables across the southwest-northeast productivity gradient spanning the two study areas).

\section{Regression modeling}

Both the basal area (BA) and tree density (TD) response variables were positively skewed, causing poor model fits at the tails of a distribution because ordinary least squares (OLS) regression assumes a normal distribution in the response variable. Therefore, square root (sqrt) and natural logarithm (ln) transforms were applied to the response variables in a preliminary analysis, both of which produced normal model residuals. Only the natural logarithm transformation was pursued for the reanalysis presented in this paper, as Hudak et al. (2005) produced better model statistics (higher $R^{2}$ and adjusted $R^{2}$ and lower $\left.\mathrm{SE}\right)$ predicting $\ln (\mathrm{BA}+1)$ and $\ln (\mathrm{TD}+1)$ than predicting sqrt(BA) and sqrt(TD). (Adding 1 to each variable before natural logarithm transforming was necessary due to BA and TD values $=0$ at the 11 Moscow Mountain plots lacking trees $\geq 12.7 \mathrm{~cm}$ dbh; the effect of this was cancelled by subtracting 1 from the final, back-transformed predictions.)

The 26 predictor variables available for predicting $\ln (\mathrm{BA}+1)$ and $\ln (\mathrm{TD}+1)$ were $X, Y$, and $Z$ geographic locations obtained with the GPS at plot centers (3), ALI image pixel statistics (11), and statistics derived from lidar-derived intensity (4), height 
Table 1. Predictor variables used for multiple linear regression modeling of natural-logarithmtransformed basal area and tree density.

\begin{tabular}{|c|c|}
\hline Predictor variable & Description \\
\hline \multicolumn{2}{|l|}{ Geographic } \\
\hline Easting & UTM (Zone 11) easting at plot center \\
\hline Northing & UTM (Zone 11) northing at plot center \\
\hline Elevation & Elevation $(\mathrm{m})$ above mean sea level at plot center \\
\hline \multicolumn{2}{|c|}{ Advanced land imager (ALI) } \\
\hline $\mathrm{B} 1_{\text {mean }}$ & Mean of $30 \mathrm{~m}$ ALI band 1 pixels intersecting plot \\
\hline $\mathrm{B} 2_{\text {mean }}$ & Mean of $30 \mathrm{~m} \mathrm{ALI}$ band 2 pixels intersecting plot \\
\hline $\mathrm{B} 33_{\text {mean }}$ & Mean of $30 \mathrm{~m} \mathrm{ALI}$ band 3 pixels intersecting plot \\
\hline $\mathrm{B} 4_{\text {mean }}$ & Mean of $30 \mathrm{~m}$ ALI band 4 pixels intersecting plot \\
\hline $\mathrm{B} 5_{\text {mean }}$ & Mean of $30 \mathrm{~m}$ ALI band 5 pixels intersecting plot \\
\hline $\mathrm{B} 6_{\text {mean }}$ & Mean of $30 \mathrm{~m} \mathrm{ALI}$ band 6 pixels intersecting plot \\
\hline $\mathrm{B} 7_{\text {mean }}$ & Mean of $30 \mathrm{~m}$ ALI band 7 pixels intersecting plot \\
\hline $\mathrm{B} 8_{\text {mean }}$ & Mean of $30 \mathrm{~m} \mathrm{ALI}$ band 8 pixels intersecting plot \\
\hline $\mathrm{B} 9$ mean & Mean of $30 \mathrm{~m}$ ALI band 9 pixels intersecting plot \\
\hline $\mathrm{PAN}_{\text {mean }}$ & Mean of 10 m PAN band pixels intersecting plot \\
\hline $\mathrm{PAN}_{\text {std }}$ & Standard deviation of $10 \mathrm{~m}$ PAN band pixels intersecting plot \\
\hline \multicolumn{2}{|r|}{$e^{2}$} \\
\hline \multicolumn{2}{|l|}{ Intensity } \\
\hline $\mathrm{INT}_{\text {mean }}$ & Mean of $2 \mathrm{~m}$ intensity pixels intersecting plot \\
\hline $\mathrm{INT}_{\text {std }}$ & Standard deviation of $2 \mathrm{~m}$ intensity pixels intersecting plot \\
\hline $\mathrm{INT}_{\min }$ & Minimum of $2 \mathrm{~m}$ intensity pixels intersecting plot \\
\hline $\mathrm{INT}_{\max }$ & Maximum of $2 \mathrm{~m}$ intensity pixels intersecting plot \\
\hline \multicolumn{2}{|r|}{ 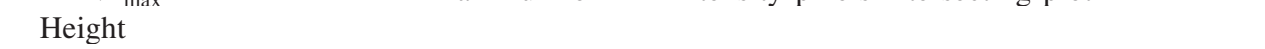 } \\
\hline $\mathrm{HT}_{\text {mean }}$ & Mean of $6 \mathrm{~m}$ height pixels intersecting plot \\
\hline $\mathrm{HT}_{\text {std }}$ & Standard deviation of $6 \mathrm{~m}$ height pixels intersecting plot \\
\hline $\mathrm{HT}_{\min }$ & Minimum of $6 \mathrm{~m}$ height pixels intersecting plot \\
\hline $\mathrm{HT}_{\max }$ & Maximum of $6 \mathrm{~m}$ height pixels intersecting plot \\
\hline \multicolumn{2}{|l|}{ Canopy cover } \\
\hline $\mathrm{CC}_{\text {mean }}$ & Mean of $6 \mathrm{~m}$ canopy cover pixels intersecting plot \\
\hline $\mathrm{CC}_{\text {std }}$ & Standard deviation of $6 \mathrm{~m}$ canopy cover pixels intersecting plot \\
\hline $\mathrm{CC}_{\text {min }}$ & Minimum of $6 \mathrm{~m}$ canopy cover pixels intersecting plot \\
\hline $\mathrm{CC}_{\max }$ & Maximum of $6 \mathrm{~m}$ canopy cover pixels intersecting plot \\
\hline
\end{tabular}

(4), and canopy cover (4) images (Table 1). Two regression modeling approaches (stepwise, followed by best subsets) were employed to objectively choose the best linear models for predicting BA and TD from this suite of predictors. Stepwise model selection adds (forward mode) or drops (backward mode) predictor variables, one at a time, until minimizing the AIC statistic indicative of relative model fit (Akaike, 1973; 1974). We used the "Im" linear model function in R (R Development Core Team, 2004) to build the full model, then subset it using the stepAIC function (available in the MASS library of R), operating in both forward and backward modes. Stepwise model selection effectively traces only one path through the predictor variables, whereas best-subsets regression exhaustively searches all pathways to choose the best variable subset for a given number of predictors. Thus a subset of $n$ predictors selected via the best-subsets approach usually produces better model statistics than the same number of predictors selected via the stepwise approach.

Once we had the stepwise model results, we proceeded with the best-subsets method. For this method we used the regsubsets function (available in the "leaps" package of R), which selects the best regression subsets through exhaustive search. The method requires the user to set a maximum number of variables in a subset model (the argument "nvmax"). We set this parameter to match the number of variables found in the stepwise selection. The model statistic used to determine best subsets was Mallows (1973) Cp statistic, which compares the error sum of squares for a reduced model to the mean square error of the full model:

$\mathrm{Cp}=\mathrm{SSE} / \mathrm{MSE}_{\mathrm{full}}-N+2 p$

where SSE is the error sum of squares of the reduced model with $p$ parameters (including the intercept), $\mathrm{MSE}_{\mathrm{full}}$ is the mean square error of the full model (complete set of $p$ ), and $N$ is the number of samples. A desirable model is indicated if $\mathrm{Cp}$ is approximately equal to $p$; the combination of predictors that minimizes Mallows Cp over all possible subsets is considered the best subset.

To define a reasonable minimum number of predictors for a model subset, an ANOVA test was performed to compare each best subset (for a given variable count) to the overall best subset 
Table 2. Multiple linear regression models for predicting natural-logarithm-transformed basal area and tree density from geographic, ALI, or lidar variable groups.

\begin{tabular}{|c|c|c|c|c|c|}
\hline Method & Selected variables & $R^{2}$ & Adjusted $R^{2}$ & Residual SE & AIC \\
\hline \multicolumn{6}{|l|}{ Basal area } \\
\hline Geographic & Easting, northing, elevation & 0.0946 & 0.0777 & 31.3400 & 1140.80 \\
\hline ALI & $\mathrm{B} 1_{\text {mean }}, \mathrm{B} 2_{\text {mean }}, \mathrm{PAN} \mathrm{N}_{\text {mean }}, \mathrm{PAN} \mathrm{N}_{\text {std }}$ & 0.5599 & 0.5489 & 0.8540 & -47.15 \\
\hline \multicolumn{6}{|c|}{ 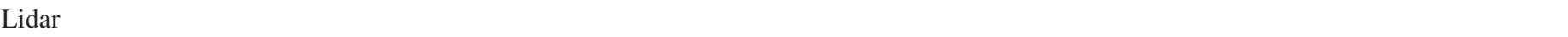 } \\
\hline All lidar & $\mathrm{INT}_{\text {mean }}, \mathrm{Ht}_{\text {mean }}, \mathrm{Ht}_{\text {std }}, \mathrm{Ht}_{\text {min }}, \mathrm{CC}_{\text {mean }}, \mathrm{CC}_{\text {std }}$ & 0.8941 & 0.8901 & 0.4216 & -278.17 \\
\hline Intensity & $\mathrm{INT}_{\text {mean }}, \mathrm{INT}_{\text {std }}, \mathrm{INT}_{\text {min }}$ & 0.7779 & 0.7738 & 0.6048 & -161.98 \\
\hline Height & $\mathrm{HT}_{\text {mean }}, \mathrm{HT}_{\max }$ & 0.7958 & 0.7960 & 0.5744 & -180.01 \\
\hline Canopy cover & $\mathrm{CC}_{\text {mean }}, \mathrm{CC}_{\text {std }}, \mathrm{CC}_{\text {min }}$ & 0.7058 & 0.7003 & 0.6962 & -115.57 \\
\hline \multicolumn{6}{|l|}{ Tree density } \\
\hline Geographic & Easting, northing, elevation & 0.0871 & 0.0700 & 368.1000 & 1953.69 \\
\hline ALI & $\mathrm{B} 1_{\text {mean }}, \mathrm{B} 2_{\text {mean }}, \mathrm{B} 7_{\text {mean }}, \mathrm{B} 8_{\text {mean }}, \mathrm{B} 9_{\text {mean }}, \mathrm{PAN} \mathrm{N}_{\text {mean }}, \mathrm{PAN} \mathrm{N}_{\text {std }}$ & 0.6568 & 0.6415 & 1.0390 & 20.32 \\
\hline \multicolumn{6}{|c|}{ 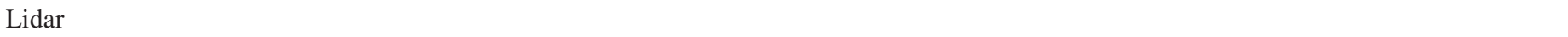 } \\
\hline All lidar & $\mathrm{INT}_{\text {mean }}, \mathrm{INT}_{\text {std }}, \mathrm{INT}_{\text {min }}, \mathrm{CC}_{\text {mean }}, \mathrm{CC}_{\text {max }}$ & 0.8698 & 0.8657 & 0.6358 & -143.56 \\
\hline Intensity & $\mathrm{INT}_{\text {mean }}, \mathrm{INT}_{\text {std }}, \mathrm{INT}_{\min }$ & 0.7779 & 0.7737 & 0.8252 & -59.45 \\
\hline Height & $\mathrm{HT}_{\text {mean }}, \mathrm{HT}_{\max }$ & 0.4962 & 0.4900 & 1.2390 & 73.67 \\
\hline Canopy cover & $\mathrm{CC}_{\text {mean }}, \mathrm{CC}_{\mathrm{std}}, \mathrm{CC}_{\min }, \mathrm{CC}_{\max }$ & 0.8354 & 0.8313 & 0.7126 & -106.87 \\
\hline
\end{tabular}

Note: Variable groups were best subsets selected based on Mallows (1973) Cp statistic.

(having the lowest AIC overall). When a significant difference was found, model subsets having fewer predictor variables were not considered. In summary, this strategy for defining maximum and minimum predictor variable counts resulted in a suite of candidate regression models having comparable AIC statistics.

For small to medium sample sizes $(N / p<40$, as was the case in our study), there is a non-negligible tendency for the AIC to be biased towards overfit models (Hurvich and Tsai, 1989). Therefore we also calculated a corrected AIC statistic, AICc (Sugiura, 1978), which more severely penalizes the model for the parameter count:

$\mathrm{AICc}=\mathrm{AIC}+2 p(p+1) /(N-p-1)$

where, as before, $p$ is the number of parameters, and $N$ is the number of samples. Our default choice as the "best" model to choose for mapping was the model that minimized the AICc statistic, although other candidate models that differ from the best model in AIC statistics by $<2$ are also supported (Burnham and Anderson, 1998).

\section{Results}

Higher $R^{2}$ and adjusted $R^{2}$ statistics, and lower residual error and AIC indicated better predictive models. The lidar-derived variables were better predictors of BA and TD than the ALI variables, which were in turn much better predictors than the geographic variables (Table 2). The ALI variables explained more variance in TD than in BA. Lidar height variables were the best predictors of BA, followed by the intensity variables; lidar-derived cover variables were the best predictors of TD, again followed by the intensity variables. Two of three variable groups derived from lidar (intensity and canopy cover) were better predictors of BA and TD than the ALI variables, but the
ALI variables better predicted TD than the lidar height variables (Table 2).

As would be expected, the full models including all predictor variables produced the highest $R^{2}$ statistics (Table 3) but were grossly overfit. The number of variables selected from the full models via stepwise regression to predict BA and TD was 14 and 15 , respectively. Alternative models having the same number or fewer variables were selected via best-subsets regression. Table 3 lists the candidate BA and TD models. Each list is bounded on the top by the corresponding full model and on the bottom by the model having the fewest parameters, but a significantly worse fit than the best model (lowest AICc). The best BA model consisted of 12 predictor variables, and the best TD model consisted of 10 predictor variables. Tables $\mathbf{4}$ and $\mathbf{5}$ provide more complete statistics for these selected models, along with the variable coefficients used to generate maps.

A cross-validation procedure (leave-one-out) was used to produce 165 independent predictions of natural-logarithmtransformed BA and TD to compare with the natural-logarithmtransformed observations (Figures 2a, 2b). The standard deviation of the cross-validation residuals (BA, 0.3929; TD, $0.6375)$ was only slightly greater than that of the model residuals (BA, 0.3583; TD, 0.5910). These independent predictions were subsequently back-transformed and correlated against observations on the natural scale (Figures 2c, 2d). Pearson's correlations of predictions versus observations of BA declined from 0.907 to 0.895 for full-model predictions and cross-validation predictions, respectively. Pearson's correlations of predictions versus observations of TD declined from 0.774 to 0.737 for full-model predictions and crossvalidation predictions, respectively. These small differences in full-model versus cross-validation model statistics are evidence for robust models.

Although not visually apparent (Figures 2c, 2d), applying the inverse natural logarithm transformation to convert the 


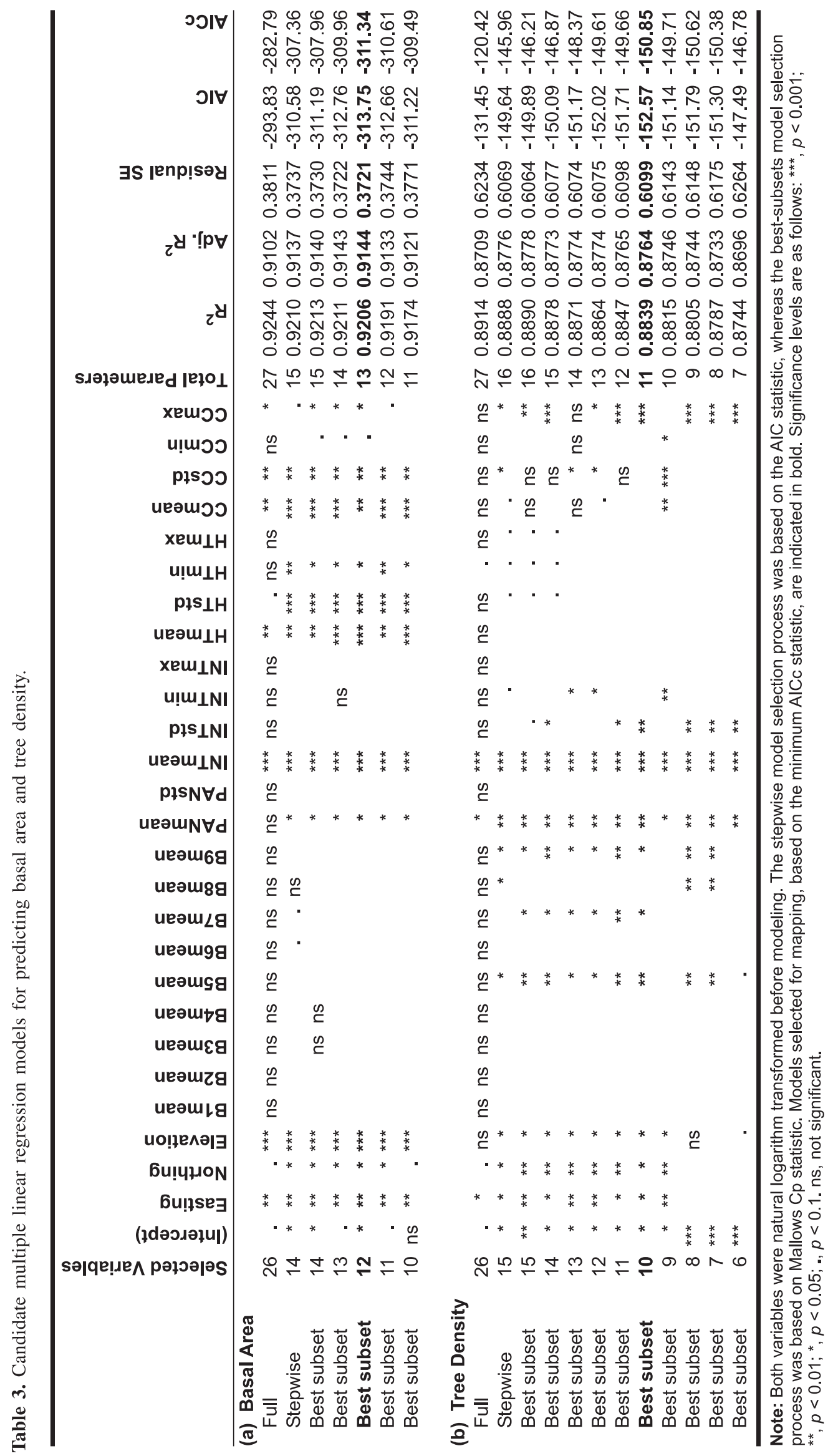


Table 4. Parameters, coefficients, and statistics for the model used to map basal area (natural logarithm transformed).

\begin{tabular}{llllll}
\hline Parameter & Estimate & SE & $t$ value & $\operatorname{Pr}(>|t|)$ & Significance \\
\hline Intercept & $-4.05 \times 10^{1}$ & $2.04 \times 10^{1}$ & -1.981 & $4.9407 \times 10^{-2}$ & $*$ \\
Easting & $-1.23 \times 10^{-5}$ & $3.80 \times 10^{-6}$ & -3.244 & $1.4480 \times 10^{-3}$ & $* *$ \\
Northing & $9.67 \times 10^{-6}$ & $4.32 \times 10^{-6}$ & 2.237 & $2.6750 \times 10^{-2}$ & $*$ \\
Elevation & $1.04 \times 10^{-3}$ & $1.81 \times 10^{-4}$ & 5.713 & $5.6700 \times 10^{-8}$ & $* * *$ \\
PAN $_{\text {mean }}$ & $-9.18 \times 10^{-4}$ & $3.68 \times 10^{-4}$ & -2.495 & $1.3675 \times 10^{-2}$ & $*$ \\
$\mathrm{INT}_{\text {mean }}$ & $-2.39 \times 10^{-2}$ & $4.99 \times 10^{-3}$ & -4.794 & $3.8600 \times 10^{-6}$ & $* * *$ \\
$\mathrm{HT}_{\text {mean }}$ & $3.56 \times 10^{-2}$ & $1.02 \times 10^{-2}$ & 3.492 & $6.2800 \times 10^{-4}$ & $* * *$ \\
$\mathrm{HT}_{\text {std }}$ & $7.22 \times 10^{-2}$ & $1.75 \times 10^{-2}$ & 4.126 & $6.0500 \times 10^{-5}$ & $* * *$ \\
$\mathrm{HT}_{\text {min }}$ & $2.22 \times 10^{-2}$ & $9.46 \times 10^{-3}$ & 2.342 & $2.0454 \times 10^{-2}$ & $*$ \\
$\mathrm{CC}_{\text {mean }}$ & $1.74 \times 10^{-2}$ & $5.21 \times 10^{-3}$ & 3.342 & $1.0470 \times 10^{-3}$ & $* *$ \\
$\mathrm{CC}_{\text {std }}$ & $4.90 \times 10^{-2}$ & $1.56 \times 10^{-2}$ & 3.144 & $2.0060 \times 10^{-3}$ & $* *$ \\
$\mathrm{CC}_{\text {min }}$ & $8.45 \times 10^{-3}$ & $4.98 \times 10^{-3}$ & 1.695 & $9.2107 \times 10^{-2}$ & $*$ \\
$\mathrm{CC}_{\text {max }}$ & $-1.46 \times 10^{-2}$ & $6.06 \times 10^{-3}$ & -2.407 & $1.7288 \times 10^{-2}$ & $*$ \\
\hline
\end{tabular}

Note: Regression sum of squares $=244.138$ at 12 degrees of freedom $(\mathrm{df})$; error sum of squares $=21.049$ at $152 \mathrm{df}$; mean square error $=0.1385 ;$ residual standard error $=0.3721 ;$ multiple $R^{2}=0.9206$; adjusted $R^{2}=0.9144 ; F$ statistic $=146.9$ on 12 and $152 \mathrm{df}\left(p<2.20 \times 10^{-16}\right)$. Significance levels are as follows: ***, $p<0.001 ; * *, p<0.01 ; *, p<0.05 ; ., p<0.1$.

Table 5. Parameters, coefficients, and statistics for the model used to map tree density (natural logarithm transformed).

\begin{tabular}{|c|c|c|c|c|c|}
\hline Parameter & Estimate & SE & $t$ value & $\operatorname{Pr}(>|t|)$ & Significance \\
\hline Intercept & $-7.15 \times 10^{1}$ & $3.15 \times 10^{1}$ & -2.266 & $2.4850 \times 10^{-2}$ & $*$ \\
\hline Easting & $-1.42 \times 10^{-5}$ & $6.00 \times 10^{-6}$ & -2.360 & $1.9550 \times 10^{-2}$ & $*$ \\
\hline Northing & $1.63 \times 10^{-5}$ & $6.63 \times 10^{-6}$ & 2.462 & $1.4940 \times 10^{-2}$ & $*$ \\
\hline Elevation & $5.62 \times 10^{-4}$ & $2.83 \times 10^{-4}$ & 1.987 & $4.8700 \times 10^{-2}$ & $*$ \\
\hline $\mathrm{B} 5_{\text {mean }}$ & $1.24 \times 10^{-3}$ & $4.31 \times 10^{-4}$ & 2.874 & $4.6200 \times 10^{-3}$ & $* *$ \\
\hline $\mathrm{B} 7_{\text {mean }}$ & $-3.57 \times 10^{-3}$ & $1.45 \times 10^{-3}$ & -2.461 & $1.5000 \times 10^{-2}$ & $*$ \\
\hline B9 & $2.51 \times 10^{-2}$ & $9.63 \times 10^{-3}$ & 2.607 & $1.0030 \times 10^{-2}$ & $*$ \\
\hline $\mathrm{PAN}_{\text {mean }}$ & $-1.88 \times 10^{-3}$ & $6.72 \times 10^{-4}$ & -2.797 & $5.8200 \times 10^{-3}$ & $* *$ \\
\hline $\mathrm{INT}_{\text {mean }}$ & $-3.54 \times 10^{-2}$ & $4.88 \times 10^{-3}$ & -7.261 & $1.7800 \times 10^{-11}$ & $* * *$ \\
\hline $\mathrm{INT}_{\text {std }}$ & $4.12 \times 10^{-2}$ & $1.37 \times 10^{-2}$ & 3.003 & $3.1200 \times 10^{-3}$ & $* *$ \\
\hline $\mathrm{CC}_{\max }$ & $3.49 \times 10^{-2}$ & $3.88 \times 10^{-3}$ & 8.992 & $8.3600 \times 10^{-16}$ & $* * *$ \\
\hline
\end{tabular}

Note: Regression sum of squares $=436.288$ at 10 degrees of freedom $(\mathrm{df})$; error sum of squares $=57.279$ at $154 \mathrm{df}$; mean square error $=0.3719$; residual standard error $=0.6099$; multiple $R^{2}=0.8839$; adjusted $R^{2}=0.8764 ; F$ statistic $=117.3$ on 10 and $154 \mathrm{df}\left(p<2.20 \times 10^{-16}\right)$. Significance levels are as follows: $* * *, p<0.001 ; * *, p<0.01 ; *, p<0.05$.

natural-logarithm-normal predictions back to the natural scale introduces a negative bias that increases in proportion to the effect of the transformation (Moeur, 1981), i.e., the larger values are disproportionately affected. This bias can be approximated by adding one half of the residual variance to the prediction on the natural logarithm scale. On the natural scale, this amounts to multiplying the prediction by $\exp (0.5 \times \mathrm{MSE})$, where MSE is the mean square error of the residuals (Baskerville, 1972). Thus the MSEs from the BA (0.1385) and TD (0.3719) models (Tables 4, 5) were substituted into this equation to calculate correction factors of 1.0717 (BA) and 1.2044 (TD); when multiplied with the back-transformed predictions, these correction factors slightly overestimated the mean BA by $2.1 \mathrm{~m}^{2} /$ ha and underestimated the mean TD by 19.2 trees/ha (Table 6). In general, the distribution of predictions better matched the distribution of observations after bias correction than before bias correction (Table 6).

The chosen BA and TD models (Tables 4, 5) were applied to the image layers selected as predictor variables by the models.
The output layers were then back-transformed to the natural scale, the value 1 was subtracted from each layer (to cancel the effect of adding 1 to $\mathrm{BA}$ and $\mathrm{TD}$ in the original transformations), and the calculated correction factors of 1.0717 (BA) and 1.2044 (TD) were applied. The BA and TD layers for the St. Joe Woodlands appear greener than those for Moscow Mountain, since much of the periphery of the latter is agricultural and because of the regional biomass and productivity gradient that spans both study areas (Figure 3).

\section{Discussion}

Applying the natural logarithm transform to the BA and TD response variables used in this analysis greatly improved the performance of the predictive models (Hudak et al., 2005). Generalized linear models (GLM), which require no transformation of a skewed response variable, could also be applied appropriately as an alternative. Using GLM would 

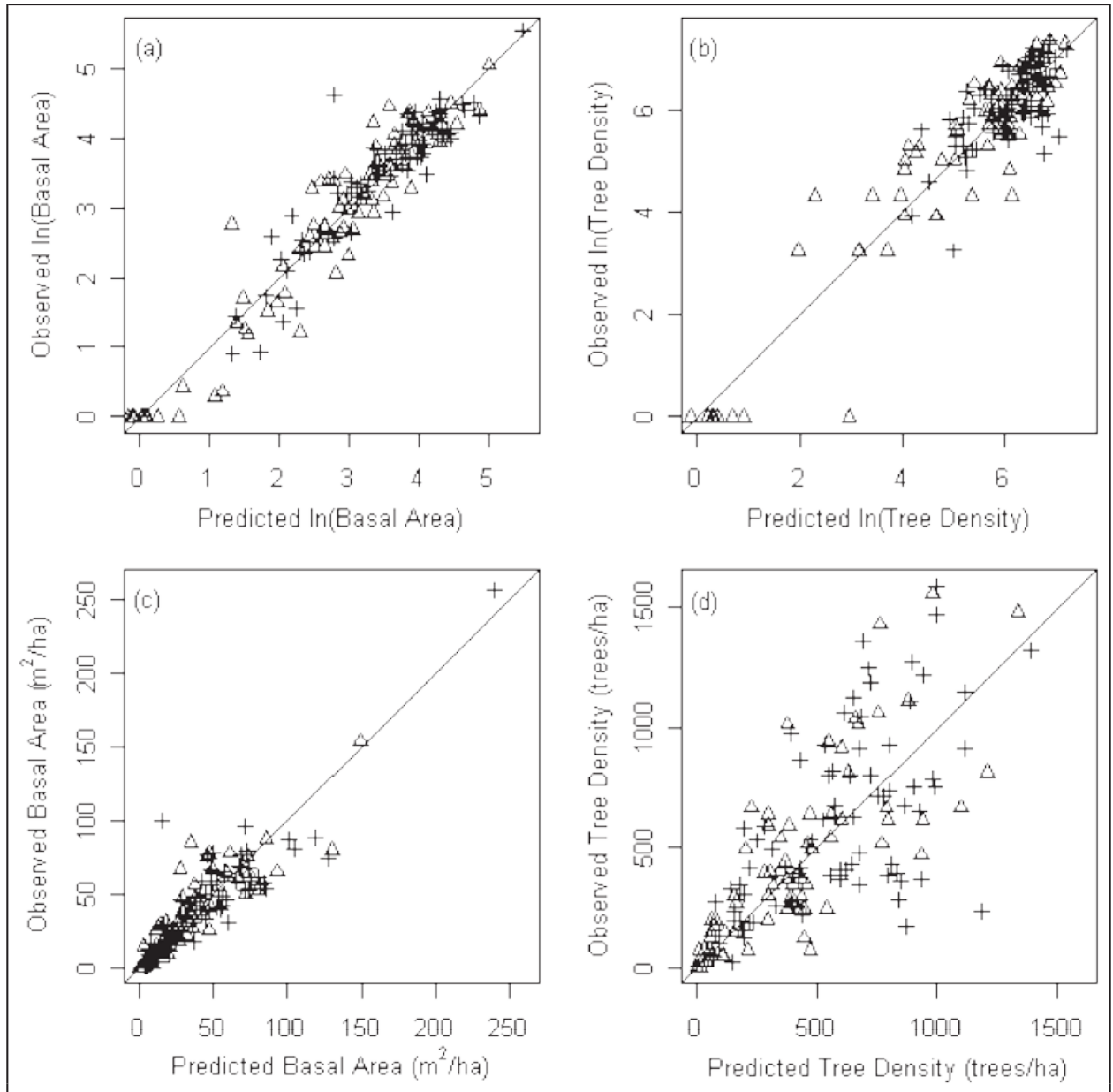

Figure 2. Scatterplots of cross-validation predictions versus observations $(N=165)$ for natural-logarithm-transformed basal area (a) and tree density (b) and natural-scale basal area (c) and tree density (d). The two highest values in (c) are the two old-growth plots. The lines indicate 1:1 relationships. $\triangle$, Moscow Mountain plots; +, St. Joe Woodlands plots.

Table 6. Summary statistics of observed and predicted basal area $\left(\mathrm{m}^{2} / \mathrm{ha}\right)$ and tree density (trees/ha) before and after bias correction for the inverse natural logarithm transformation.

\begin{tabular}{|c|c|c|c|c|c|c|}
\hline & Min. & $\begin{array}{l}\text { First } \\
\text { quartile }\end{array}$ & Median & Mean & $\begin{array}{l}\text { Third } \\
\text { quartile }\end{array}$ & Max. \\
\hline \multicolumn{7}{|l|}{ Basal area } \\
\hline Observations & 0 & 12.04 & 30.24 & 36.39 & 55.81 & 255.40 \\
\hline Predictions after back-transformation & -0.1358 & 11.87 & 28.70 & 35.92 & 52.97 & 241.70 \\
\hline Predictions corrected for transformation bias & -0.1455 & 12.72 & 30.75 & 38.49 & 56.77 & 259.00 \\
\hline \multicolumn{7}{|l|}{ Tree density } \\
\hline Observations & 0 & 197.7 & 395.4 & 492.0 & 679.5 & 1594.0 \\
\hline Predictions after back-transformation & -0.1091 & 193.3 & 419.5 & 463.3 & 700.8 & 1388.0 \\
\hline Predictions corrected for transformation bias & -0.1114 & 197.3 & 428.1 & 472.8 & 715.1 & 1417.0 \\
\hline
\end{tabular}

circumvent the need to transform and subsequently correct for a transformation bias, but in our case we believe that we have adequately adjusted for this bias (Table 6). By generating predictions on a natural scale directly, GLM would facilitate model cross-validation, evaluation, and real-world interpretation (Figure 2). Since we are casting this analysis as a demonstration study, we felt it was more important to use the much more widely familiar OLS regression.

It is apparent that raw lidar datasets contain much useful information besides height measurements. The intensity values, in particular, proved surprisingly useful in this analysis, with mean intensity being the most consistent highly significant predictor among the candidate models (Table 3). This was 


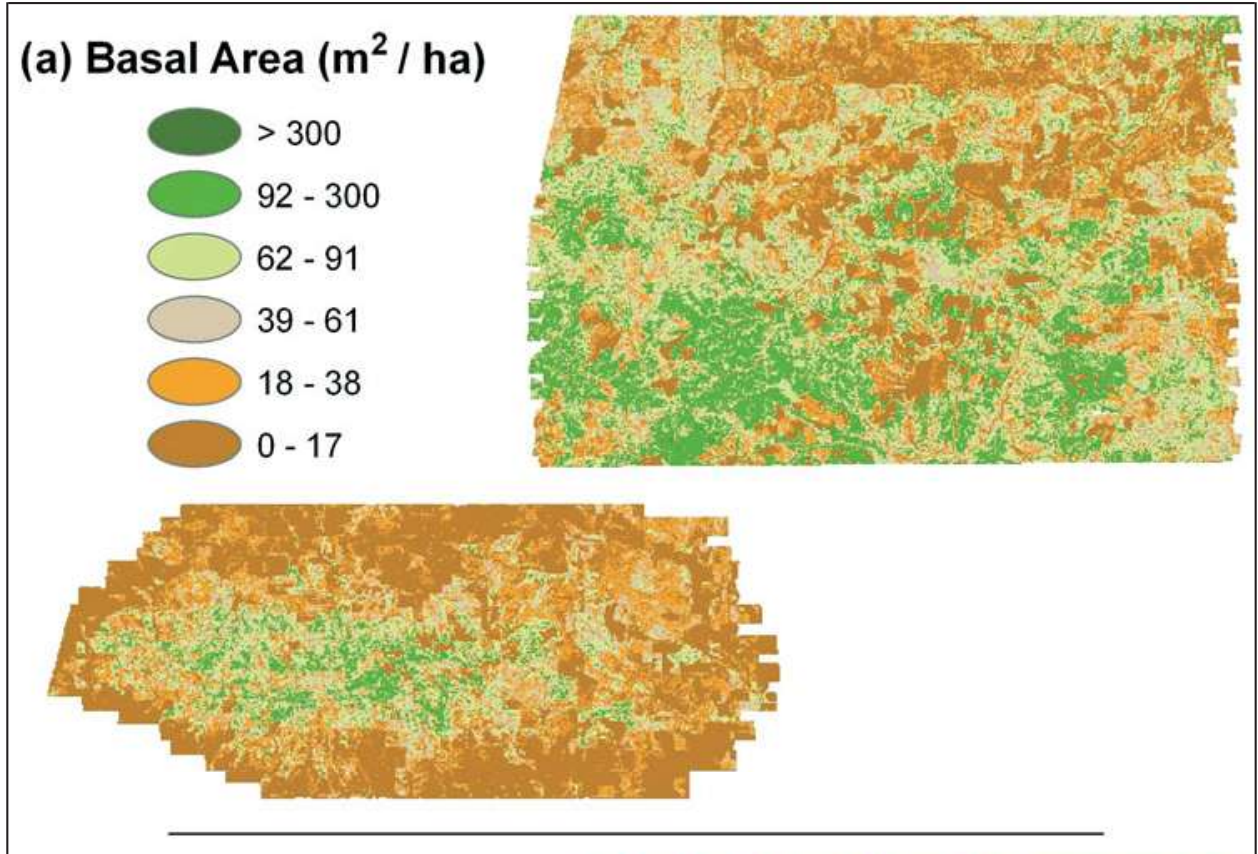

\section{(b) Tree Density (trees / ha)}
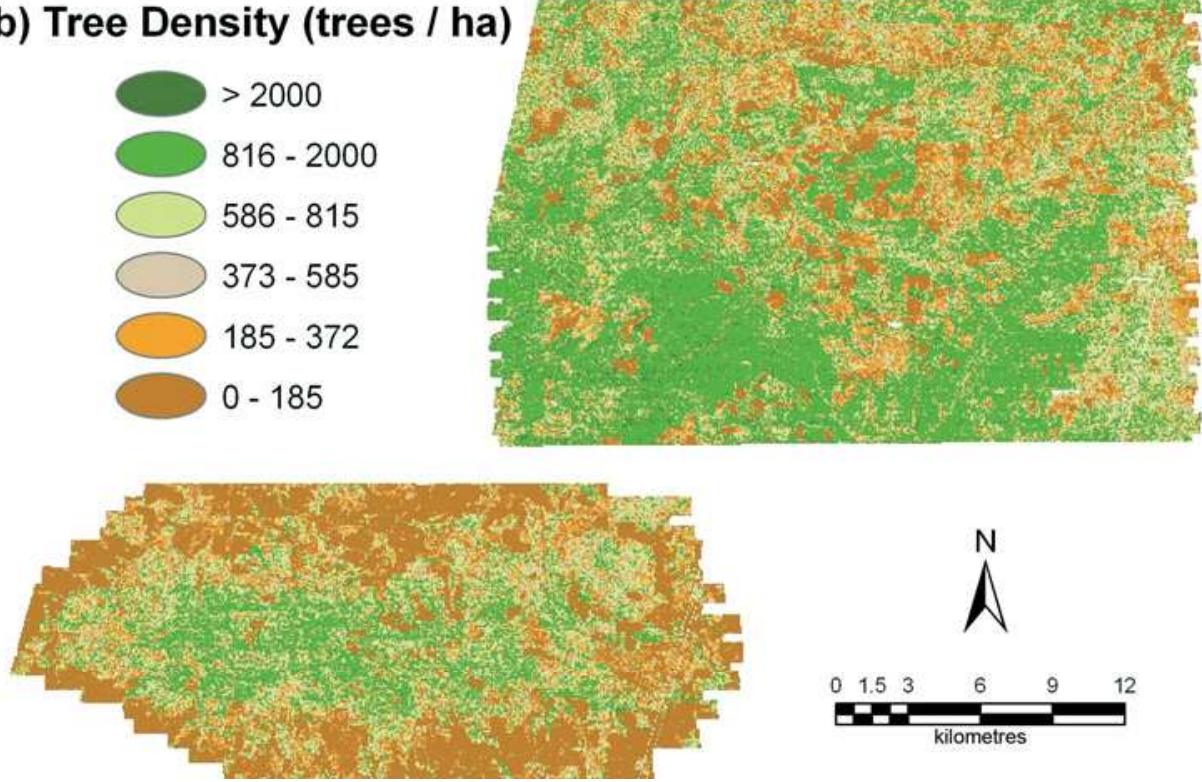

Figure 3. Predicted basal area (a) and tree density (b) maps for Moscow Mountain and the St. Joe Woodlands. Note that the western edges of the maps are cropped (compare to Figure 1) because these areas lie outside of the ALI image swaths. The parallel rows of white dots near the southeastern corners of the tree density maps are due to a dead detector (http://eo1. usgs.gov/userGuide/ali_process.html) in the band 7 image input into the tree density model. Other white areas in the maps are a consequence of lidar data dropouts.

informative, as intensity data typically have not been used in vegetation modeling and mapping. Their utility needs to be better evaluated and exploited. Our simple measure of canopy cover explained more variation in BA and TD than the ALI image data (Tables 2, 3). Calculating the percentage of nonground returns within a cell is only possible, however, if using the filtered point data, which are not typically provided by lidar vendors. We recommend obtaining the raw lidar data from the vendor and then filtering these data with the PCF model to differentiate ground from nonground returns (http:// forest.moscowfsl.wsu.edu/gems/lidar).

The lidar-derived predictor variables proved more useful than the ALI variables (Table 2). The addition of ALI variables to the models did not improve them much over models based on lidar variables alone. The lidar-derived intensity and canopy cover variables are evidently more sensitive to canopy structural variation at the plot scale of sampling. That the $10 \mathrm{~m}$ ALI panchromatic band was the ALI predictor variable most 
consistently selected among the candidate models supports this argument (Table 3). The 0.09 ha area of a $30 \mathrm{~m}$ pixel is slightly larger than the area of our field plots, meaning several $10 \mathrm{~m}$ image pixels will factor into means calculated within plots, and a plot could intersect as few as one $30 \mathrm{~m}$ pixel. This suggests that relationships between plot and image data would worsen with coarser resolution image data.

The two response variables chosen for this analysis were purely structural. The lidar canopy height variables were more influential in predicting $\mathrm{BA}$ than $\mathrm{TD}$, and the lidar canopy cover variables were more influential in predicting TD than BA. This was expected, given that larger trees are also taller, where height measures will be more sensitive, whereas TD varies more in the horizontal dimension, where cover measures will be more sensitive. The ALI image, which here proved not so helpful for mapping canopy structure, could be more useful for mapping canopy composition or perhaps habitat type, which varies more in the spectral domain than canopy structure. Inclusion of other multispectral images (e.g., Landsat) from various times during the growing season, by capturing phenological variability, might prove profitable for mapping composition. Moreover, aspect is an important determinant of forest structure and composition in this mountainous region, making a topographic-derived variable such as solar insolation potentially useful.

Minimizing the number of parameters was an important consideration, but not our only consideration, in choosing the best models for mapping. For predicting each response variable, we also sought a model with predictor variables similar to those of the other candidate models. For instance, we were less comfortable with the nine-variable TD model than the selected 10-variable model because the former was the only one among 10 candidate models to drop all of the ALI multispectral bands. Similarly, the eight- and seven-variable models dropped the easting and northing variables, which we preferred to include given our prior knowledge that a southwest-northeast productivity gradient exists across the study areas, which affects canopy structure. The same can be said for elevation and was our justification for including $X, Y$, and $Z$ geographic location predictors in the first place. Consistency and objectivity were other considerations. Since the 10-variable TD model that we preferred had the lowest SE and AICc values among the other candidate TD models, we applied the same criteria to choose the 12-variable BA model over the 11-variable model, even though an ANOVA test found a less than significant difference between them $(p=0.0921)$. Differences in AIC statistics of less than two generally indicate insignificant differences between candidate models (Burnham and Anderson, 1998). We argue that in such cases other statistics (e.g., SE), or user confidence that the particular predictor variables selected are ecologically meaningful and interpretable, should be considered to choose the best model.

We wanted to model and map BA and TD across both study areas simultaneously because together they span a larger measure of the regional environmental gradient than either study area can alone. We felt justified in doing so because the landscape sampling design, tree measurements, lidar surveys, and ALI acquisitions were all accomplished in the same manner, and at very nearly the same time. The largest discrepancy was that most of the Moscow Mountain field plots were characterized in the summer of 2003, whereas the majority of St. Joe Woodlands field plots were characterized in the summer of 2004; however, a 1 year difference in growth increment is a negligible source of error relative to the field and lidar measurement errors. Sampling an adequate number of forest plots simply takes time but is essential for building robust empirical relationships with remotely sensed data. That we were successful over forests of such diverse structure and composition and in complex terrain suggests great potential for integrating multiple types of remote sensing data with field data to more efficiently map forest structure and composition attributes with sufficient accuracy.

The Idaho Panhandle National Forest consists of many public land parcels interspersed with many private lands. This common reality of multiple jurisdictions makes cooperation between land owners the most sensible strategy for regionalscale lidar acquisitions, as has been exemplified by the Puget Sound Lidar Consortium (http://duff.geology.washington.edu/ data/raster/lidar/). Until such broader scale cooperative ventures become more commonplace, forest managers with the resources to survey their spatially disconnected lands need not be deterred from acquiring disjunct lidar datasets (as costs are likely to dictate). This study, albeit at a smaller scale, corroborates the work of Lefsky et al. (2002), who found that a single regression equation based on lidar predictor variables sufficed to model aboveground biomass across three North American biomes. Further research is warranted to determine if lidar data can robustly predict forest structure attributes of interest across multiple scales, e.g., from individual tree-level crown volume to stand-level forest biomass inventory to globallevel carbon assessment.

\section{Conclusion}

Linear multiple regression models using image and lidarderived predictor variables explained $\sim 90 \%$ of variance in basal area and tree density, two fundamental forest structure attributes that have been challenging to model and map from multispectral satellite imagery alone. Lidar data far surpass moderate-resolution image data in their ability to capture forest structure variability. Satellite image data are less sensitive to attributes relating to canopy height (e.g., basal area) than attributes relating to canopy cover (e.g., tree density). Lidar intensity values, and a simple measure of vegetation cover calculated from the ratio of nonground to total returns, may be as informative as the height measurements themselves for modeling basal area, tree density, and other stand-level structure attributes of interest. This analysis adds to the growing body of work indicating the potential of lidar to improve forest inventory and analysis. It further illustrates the value of integration of multiple types of remote sensing data 
with field data to efficiently, objectively, and accurately characterize forests to support forest science and management.

\section{Acknowledgements}

This analysis and paper are a product of the Sustainable Forestry component of Agenda 2020, a joint effort of the US Department of Agriculture Forest Service Research and Development and the American Forest and Paper Association. Data collection was supported in part by funds provided by the Rocky Mountain Research Station, Forest Service, and US Department of Agriculture, to the University of Idaho through two Joint Venture agreements (03-JV-11222048-140 and 03JV-11222063-231), with additional funds for analysis and reporting coming from two others (04-JV-11222063-299 and 05-JV-11221663-014). Research partners included Potlatch, Inc. and Bennett Lumber Products, Inc. Curtis Kvamme, K.C. Murdock, Jacob Young, Tessa Jones, Jennifer Clawson, Bryn Parker, Kasey Prestwich, Stephanie Jenkins, Kris Poncek, and Jeri Stewart assisted in the field. We thank Andrew Lister, William Wykoff, Renate Bush, and Rudy King for their helpful review comments.

\section{References}

Akaike, H. 1973. Information theory and an extension of the maximum likelihood principle. In Proceedings of the 2nd International Symposium on Information Theory. Edited by B.N. Petrov and F. Csake. Akademiai Kiado, Budapest. pp. 267-281.

Akaike, H. 1974. A new look at the statistical model identification. IEEE Transactions on Automatic Control, Vol. AC-19, pp. 716-723.

Baskerville, G.L. 1972. Use of logarithmic regression in the estimation of plant biomass. Canadian Journal of Forest Research, Vol. 2, pp. 49-53.

Bryant, R.B., Moran, M.S., Mcelroy, S.A., Holifield, C.D., Thome, K.J., Miura, T., and Biggar, S.F. 2003. Data continuity of Earth Observing-1 (EO-1) Advanced Land Imager (ALI) and Landsat TM and ETM+. IEEE Transactions on Geoscience and Remote Sensing, Vol. 41, pp. 1204-1214.

Burnham, K.P., and Anderson, D.R. 1998. Model selection and inference: a practical information-theoretic approach. Springer-Verlag, New York.

Cohen, W.B., and Goward, S.N. 2004. Landsat's role in ecological applications of remote sensing. BioScience, Vol. 54, pp. 535-545.

Flood, M. 2001. Laser altimetry: from science to commercial lidar mapping. Photogrammetric Engineering \& Remote Sensing, Vol. 67, No. 11, pp. 1209-1217.

Haugerud, R.A., and Harding, D.J. 2001. Some algorithms for virtual deforestation (VDF) of lidar topographic survey data. International Archives of Photogrammetry and Remote Sensing, Vol. 34, No. 3/W4, pp. 211-217.

Helios Environmental Modeling Institute (HEMI), LLC. 2000. The solar analyst 1.0 user manual. Helios Environmental Modeling Institute (HEMI) LLC, Lawrence, Kans.

Hudak, A.T., and Wessman, C.A. 1998. Textural analysis of historical aerial photography to characterize woody plant encroachment in South African savanna. Remote Sensing of Environment, Vol. 66, pp. 317-330.
Hudak, A.T., Lefsky, M.A., Cohen, W.B., and Berterretche, M. 2002. Integration of lidar and Landsat ETM+ data for estimating and mapping forest canopy height. Remote Sensing of Environment, Vol. 82, pp. 397416.

Hudak, A.T., Evans, J.S., Falkowski, M.J., Crookston, N.L., Gessler, P.E., Morgan, P., and Smith, A.M.S. 2005. Predicting plot basal area and tree density in mixed-conifer forest from lidar and Advanced Land Imager (ALI) data. In Proceedings of the 26th Canadian Symposium on Remote Sensing, 14-16 June 2005, Wolfville, N.S. Canadian Aeronautics and Space Administration, Ottawa, Ont.

Hurvich, C.M., and Tsai, C.L. 1989. Regression and time series model selection in small samples. Biometrika, Vol. 76, pp. 297-307.

Kennedy, R.E., and Cohen, W.B. 2003. Automated designation of tie-points for image-to-image coregistration. International Journal of Remote Sensing, Vol. 24, No. 17, pp. 3467-3490.

Lefsky, M.A., Cohen, W.B., Hudak, A.T., Acker, S.A., and Ohmann, J.L. 1999. Integration of lidar, Landsat ETM+ and forest inventory data for regional forest mapping. International Archives of Photogrammetry and Remote Sensing, Vol. 32, No. 3/W14, pp. 119-126.

Lefsky, M.A., Cohen, W.B., and Spies, T.A. 2001. An evaluation of alternate remote sensing products for forest inventory, monitoring, and mapping of Douglas-fir forests in western Oregon. Canadian Journal of Forest Research, Vol. 31, No. 1, pp. 78-87.

Lefsky, M.A., Cohen, W.B., Harding, D.J., Parker, G.G., Acker, S.A., and Gower, S.T. 2002. Lidar remote sensing of above-ground biomass in three biomes. Global Ecology and Biogeography, Vol. 11, pp. 393-399.

Mallows, C.L. 1973. Some comments on Cp. Technometrics, Vol. 15, pp. 661667.

Means, J.E., Acker, S.A., Fitt, B.J., Renslow, M., Emerson, L., and Hendrix, C.J. 2000. Predicting forest stand characteristics with airborne scanning lidar. Photogrammetric Engineering \& Remote Sensing, Vol. 66, pp. 13671371.

Moeur, M. 1981. Crown width and foliage weight of northern Rocky Mountain conifers. Intermountain Forest and Range Experiment Station, US Department of Agriculture Forest Service, Ogden, Utah. Research Paper INT-283.

Nelson, R. 1984. Determining forest canopy characteristics using airborne laser data. Remote Sensing of Environment, Vol. 15, pp. 201-212.

Nemani, R., Pierce, L., Running, S., and Band, L. 1993. Forest ecosystem processes at the watershed scale: sensitivity to remotely-sensed leaf area index estimates. International Journal of Remote Sensing, Vol. 14, pp. 2519-2534.

Nilsson, M. 1996. Estimation of tree heights and stand volume using an airborne lidar system. Remote Sensing of Environment, Vol. 56, pp. 1-7.

Pocewicz, A.L., Gessler, P.E., and Robinson, A.P. 2004. The relationship between effective plant area index and Landsat spectral response across elevation, solar insolation, and spatial scales, in a northern Idaho forest. Canadian Journal of Forest Research, Vol. 34, No. 2, pp. 465-480.

Popescu, S.C., and Wynne, R.H. 2004. Seeing the trees in the forest: using lidar and multispectral data fusion with local filtering and variable window size for estimating tree height. Photogrammetric Engineering \& Remote Sensing, Vol. 70, No. 5, pp. 589-604.

R Development Core Team. 2004. R: A language and environment for statistical computing. R Foundation for Statistical Computing, Vienna, 
Vol. 32, No. 2, April/avril 2006

Austria. ISBN 3-900051-07-0. Available from http://www.R-project.org. [retrieved 24 October 2004].

Sugiura, N. 1978. Further analysis of the data by Akaike's information criterion and the finite corrections. Communications in Statistics - Theory and Methods, Vol. A7, No. 1, pp. 13-26. 